Article

\title{
Ethanol Extract of Campsis grandiflora Flower and Its Organic Acid Components Have Inhibitory Effects on Autoinducer Type 1 Quorum Sensing
}

\author{
Juanmei Zhang ${ }^{1,2}$, Fenghua $\mathrm{Xu}^{1}{ }^{1}$, Lingling Yao ${ }^{1}$, Leyu Wang ${ }^{1}$, Miao Wang ${ }^{2,3, *}$ \\ and Gang Wang 2,3,* \\ 1 School of Pharmaceutical, Henan University, Kaifeng 475004, China; Zhangjm@henu.edu.cn (J.Z.); \\ xfh425xfh@163.com (F.X.); yaoll1431103011@163.com (L.Y.); 18300684730@163.com (L.W.) \\ 2 Institute of Microbial Engineering, Laboratory of Bioresource and Applied Microbiology, \\ School of Life Sciences, Hennan Univeristy, Kaifeng 475004, China \\ 3 Engineering Research Center for Applied Microbiology of Henan Province, Kaifeng 475004, China \\ * Correspondence: wangmiao@henu.edu.cn (M.W.); gwangbio@henu.edu.cn (G.W.)
}

Academic Editors: Maria do Carmo Barreto, Laila Moujir Moujir and Nelson Simões Received: 16 August 2020; Accepted: 10 October 2020; Published: 15 October 2020

\begin{abstract}
Chinese herbs are a useful resource bank for natural drug development, and have attracted considerable attention to exploit quorum sensing inhibitors (QSIs). This study was designed to screen QSIs from raw Chinese herb materials. Of the 38 common herbs examined, the ethanol extract of Campsis grandiflora flower had the strongest QSI activity. The $C$. grandiflora flower ethanol extract (CFEE) was purified by HPD600, and the QSI activities were examined in further detail. CFEE inhibited violacein production of Chromobacterium violaceum 026 in a dose-dependent manner, and inhibit the swarming abilities of Escherichia coli K-12 and Pseudomonas aeruginosa PAO1. Furthermore, CFEE could inhibited biofilm formation and destroyed mature biofilms of E. coli K-12 and P. aeruginosa PAO1. The composition of CFEE was determined by UPLC-MS/MS to distinguish active QSI compounds, and 21 compounds were identified. In addition to gallic acid and caffeic acid, two organic acids, malic acid and succinic acid, were confirmed for the first time to have autoinducer type 1 QSI activities. Therefore, CFEE is a potential QSI that could be used as a novel antimicrobial agent and should be considered for medicinal development.
\end{abstract}

Keywords: quorum sensing; Campsis grandiflora; biofilm; swarming; malic acid; succinic acid

\section{Introduction}

Since their discovery, antibiotics, have played a vital role in the treatment of bacterial infections and diseases in humans and animals [1]. However, the emergence and spread of bacterial drug resistance means that new antibiotics are needed to combat drug-resistant bacteria. Only a limited number of new antibiotics have been developed in the past 50 years [2], and infections caused by drug-resistant bacteria are currently one of the leading causes of death worldwide. Without intervention, it is expected that various "superbugs" will emerge one after the other in the future. Therefore, a major challenge for researchers is to develop novel therapies to control diseases caused by these drug-resistant pathogens.

Bacteria can perform coordinated activities, including biofilm formation, swarming motility, and virulence, and this coordination was previously thought to be restricted to multicellular organisms [3-5]. Quorum sensing (QS) was an important discovery in the field of microbiology related to the social behavior of bacteria. QS is defined as environmental signal sensing system to monitor population density of bacterial, and regulate a set of bacterial behaviors including bioluminescence, biofilm formation, virulence, swarming motility, competence, antibiotic production, 
conjugation, and sporulation [6]. Many pathogenic bacteria, including Escherichia coli O157: H7, Pseudomonas aeruginosa, Vibrio cholerae, and Salmonella enterica can produce a kind of signal molecule, Acyl hyperserine lactone (AHL), which was named autoinducer type 1 (AI-1), and many phenotypes of them are controlled by this type 1 QS. These phenotypes include the expression of virulence factors, pigment synthesis, and production of degradation enzymes $[7,8]$. Recent discoveries indicate that intercellular communication enables pathogens to rapidly build up biofilm structures to counter host immunity [9]. In addition, biofilms allow bacteria to resist a variety of extreme environments, including antibacterial substances, high temperature, high salt, and drying [10,11]. Biofilms are therefore novel targets for certain antimicrobial agents $[1,6]$. Due to their anti-QS activities, quorum-sensing inhibitors (QSIs) can eliminate bacterial pathogenicity or enhance their sensitivity to antibiotics without killing microorganisms, and do not lead to bacteria resistance [12,13]. Thus, it presents a new strategy for the development of new therapeutics against pathogenic bacteria.

AHL is a signal molecule (AI-1) that mediates the QS system of Gram-negative bacteria. Recent researches have focused on the development of AHL analogues as QSIs [14], and many types of QSIs have been reported. Small molecule compounds extracted from plants have attracted significant interest because of their safety and non-toxicity [6,15]. Previous studies on plant polyphenols and flavonoids, such as quercetin, apigenin, and kaempferol, have predominantly concentrated on their antioxidant, anti-inflammatory, and anticancer activities [16-19]. However, reports of the QSI activities of such compounds have increased rapidly in recent years [20]. Medicinal plants can provide accessible and relatively cheap herbal drugs, and thus, form an integral part of global healthcare worldwide. The broad acceptability of medicinal plants has generated interest in them as a potential source of new, affordable, and efficacious drugs to treat microbial diseases [21]. Chinese herbs are a promising natural medicine resource [22].

Natural compounds from Chinese herbs, including polyphenols, phenolic acids, flavonoids, terpenes, and other herbal ingredients, can be used as QSIs [20]. Previously, we screened natural food materials for active QSI substances, and revealed that aqueous polyphenols from Rosa rugosa flower have anti-QS activities [23]. Here, 38 kinds of Chinese herbs were screened for natural compounds with QSI activity. Active substances were selected to verify their effects on AI-1 QS-related bacterial phenotypes, including violacein synthesis, migration, and biofilm formation. This work provides the theoretical foundation for the development of new antibacterial drugs.

\section{Results and Discussion}

\subsection{QSIs Screening}

Thirty-eight flowers from plants used for Chinese herbs were screened using Chromobacterium violaceum 026. This reporter strain is a Tn'5 mutant of wild-type C. violaceum ATCC 12,472 and cannot synthesize signal molecules itself but can sense exogenous signal molecules. $\mathrm{N}$-hexanoyl-L-homoserine lactone $\left(\mathrm{C}_{6}\right.$-HSL) on the surface of the agar plates induces the violacein production of $C$. violaceum 026 in the agar. If QSIs spotted on the filter paper, violacein production will be inhibited, and a transparent, white or opaque ring around the filter paper will appear. The antibacterial activity of the Chinese herb flower extract samples was also detected.

Twelve of the 38 flower extracts, including those from Campsis grandiflora, Sanchi flower, Ple butterflybush flower, and Flos Sophorae, could inhibit violacein production of C. violaceum 026 (Table 1). Antibacterial activities of these 12 flower extracts were also analyzed. Sophora japonica Linn flower, Chimonanthus praecox, and Dendranthema morifolium (Ramat.) Tzvel displayed antibacterial activities against $C$. violaceum 026 . The purple suppressor ring around the filter paper for these three Chinese herb extracts may therefore be due to a bacteriostatic effect of these herbs on C. violaceum 026 . The other nine flower extracts that inhibited violacein production were considered to be potential QSIs. The crude ethanol extract of C. grandiflora demonstrated the strongest anti-QS activity and was selected for further experiments. 
Table 1. Screening results of 38 kinds of plant flowers used for Chinese herbs.

\begin{tabular}{ccc}
\hline & Inhibition Zone of Purple & Transparent Zone \\
\hline Campsis grandiflora & +++ & - \\
Panax notoginseng flower & ++ & - \\
Buddleja officinalis flower & ++ & - \\
Pueraria lobate flower & ++ & - \\
Lonicera japonica Thunb. & ++ & ++ \\
Sophora japonica Linn flower & + & - \\
Crocus sativus L. & + & - \\
Lavandula angustifolia Mill. & + & - \\
Jasminum sambac (L.) Ait. & + & ++ \\
Chimonanthus praecox & + & + \\
Dendranthema morifolium (Ramat.) Tzvel. & + & - \\
Prunus persica & ++ & - \\
\hline
\end{tabular}

Footer: "+", inhibition zone diameter under $9 \mathrm{~mm}$; "++", inhibition zone diameter between 9 and $14 \mathrm{~mm}$; "+++", inhibition zone diameter higher than $14 \mathrm{~mm},{ }^{-}{ }^{-}$, no inhibition zone.

C. grandiflora flower ethanol extract (CFEE) was purified by macroporous resin HPD600, and the polyphenol content in the extract was determined. Total polyphenol content of the crude ethanol extract from C. grandiflora was $247.66 \mathrm{mg} \mathrm{GA} / \mathrm{g}$, and that of the CFEE prepared in this study was $480.4 \mathrm{mg} \mathrm{GA} / \mathrm{g}$. After purification by macroporous resin, the polyphenols content of CFEE was nearly doubled. This result was likely to be the same as Rosa rugosa polyphenols in previous report of Zhang et al. [24].

\subsection{The QSI Activities of CFEE}

QSI activity was checked in the purified CFEE using the agar plate method. When $\mathrm{C}_{6}$-HSL is dotted on the filter paper, $C$. violaceum 026 produces violacein to form a purple circle (Figure 1A). While $\mathrm{C}_{6}$-HSL was coated on the plate inoculated with 026 , the entire plate will appear purple (Figure 1B), and filter papers (Diameter of $6 \mathrm{~mm}$ ) were placed on the plate to screen QSI. If QSIs are present in the testing sample which were dotted on the filter papers, white or opaque circles will appear around the filter paper on the $C$. violaceum 026 plate. If a sample induces bacteriostasis, the reporter strain cannot grow, and the filter paper will be surrounded by a transparent ring.
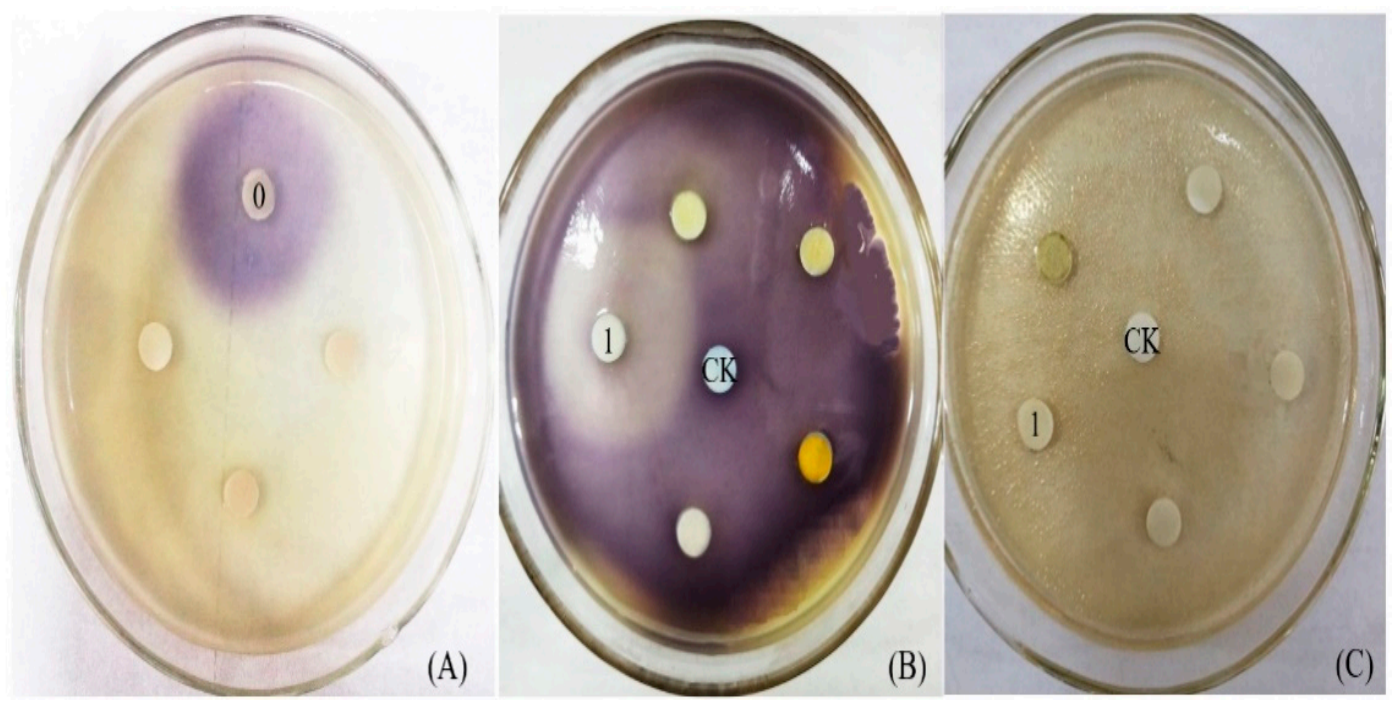

Figure 1. The QSI activity of C. grandiflora flower extract and CFEE identified by report plates. (A,C) LB agar plate incubated by $C$. violaceum 026 ; (B) LB agar plate supplemented by $\mathrm{C}_{6}-\mathrm{HSL}$ and incubated by C. violaceum 026 ; “CK”, negative control loading with methanol; “ 0 ”, $\mathrm{C}_{6}$-HSL; “ 1 ”, CFEE. 
As shown in Figure 1B, a ring without purple pigment, approximately $4.27 \mathrm{~cm}$ in diameter appeared around the filter paper loaded with CFEE, but there was no transparent ring around the filter paper (Figure 1C). This indicated that the purple suppressor ring was caused by anti-QS phenomenon rather than bacteriostatic action. Therefore, it was concluded that CFEE was a potential QSI and may contain some compounds with QSI activities. Organic extracts from plants were reported to show very promising antibacterial properties correlated with their phenolic compound content [20]. However, due to the developing bacterial resistance, researches on some antibacterial compounds have turned to their anti-QS activities, which can block the bacterial resistance. Medicinal plants contain numerous bio-active molecules, including terpenoids, polyphenols, flavonoids, tannins, anthocyanins, polyamines, cytokinins, and polysaccharides, and these can be useful to counterbalance bacterial resistance by targeting QS signaling pathways [25-28]. Therefore, the QSI activities of CFEE were further explored, and the small molecule compound composition of CFEE was analyzed.

\subsection{CFEE Inhibits the Yield of Violacein in C. violaceum 026}

The minimum inhibitory concentration (MIC) of CFEE was $1000 \mu \mathrm{g} / \mathrm{mL}$. All experiments relating to the determination of QSI activities were performed at concentrations below the MIC. To verify the QSI activity of CFEE, violacein production of $C$. violaceum 026 at different CFEE concentrations was determined. The violacein production and biomass were represented as the absorbance of OD595 and OD600, respectively. The yields of violacein did not change significantly $(p>0.1)$ at CFEE concentrations below $200 \mu \mathrm{g} / \mathrm{mL}$ (Figure 2). Increasing CFEE concentrations from 100 to $400 \mu \mathrm{g} / \mathrm{mL}$, significantly increased the inhibition of violacein production from $5.43 \%$ to $67.0 \%(0.01<p<0.05)$. Meanwhile, the biomass of $C$. violaceum 026 was not significantly $(p>0.5)$ inhibited by the concentrations of CFEE (Figure 2). Together, these data indicate that the observed decrease in violacein production is not due to CFEE inhibiting growth of $C$. violaceum 026 , but is likely due to CFEE interfering with violacein synthesis, which is regulated by QS.

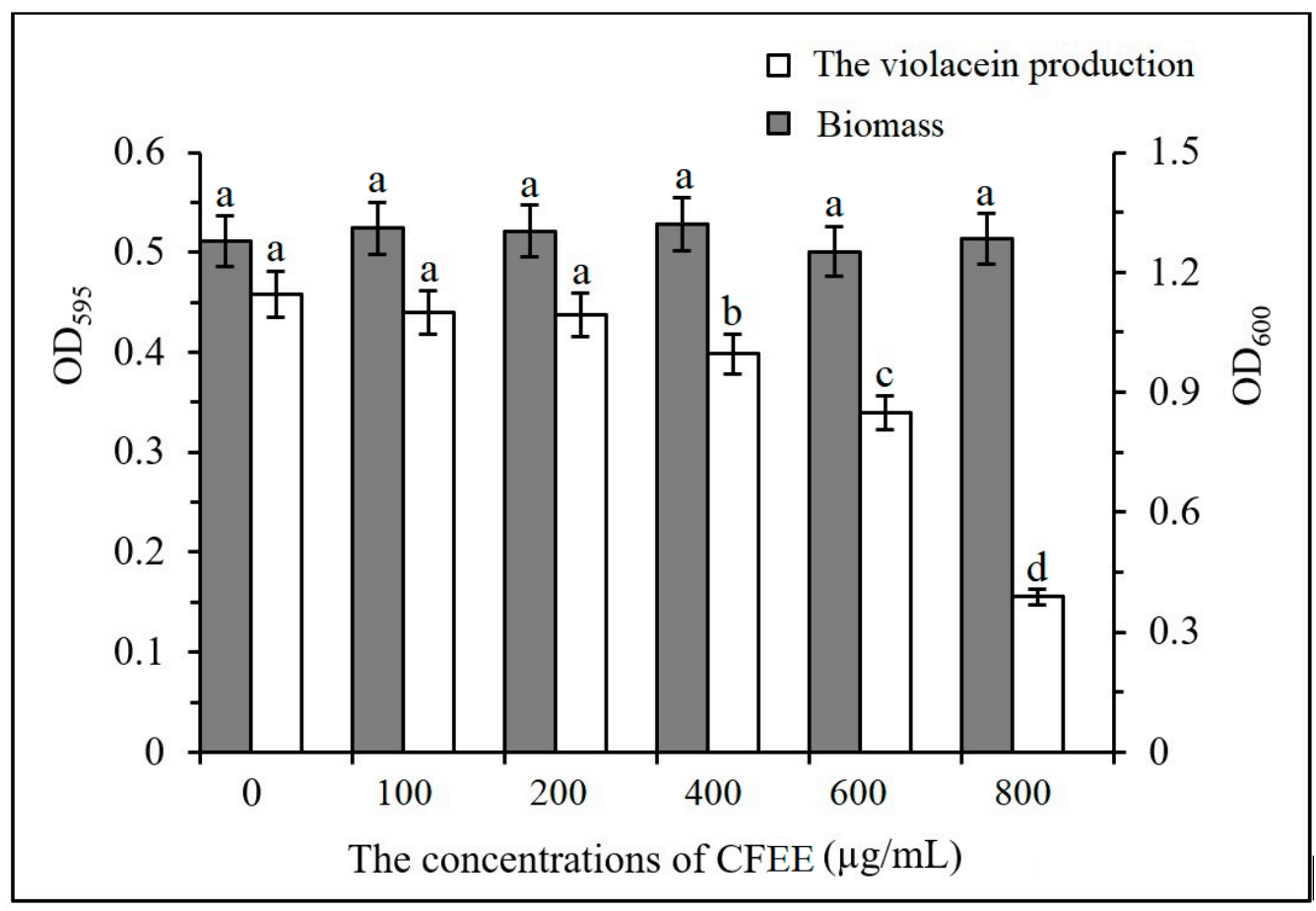

Figure 2. Biomass and violacein production of $C$. violaceum 026 when it was incubated in the LB medium with different concentrations of CFEE. Each bar represents the standard deviations of five measurements. Different letters indicate significant differences in inhibition rates. 
C. violaceum 026 is often used for screening QSIs. When the C. violaceum 026 CviR receptor is bound by exogenous C6-HSL, violacein expression regulated by the QS system is activated. Phenolic compounds can inhibit the QS system by competitively binding to the CviR receptor, thereby blocking the production of violacein [29], Thus, inhibition of C. violaceum 026 violacein production by CFEE must be the result of active QSI molecules. These molecules require identification and further study.

\subsection{CFEE Interrupts the Swarming Ability of Tested Strains}

To validate the QSI activity of CFEE, the swarming ability of E. coli K-12 and P. aeruginosa PAO1 under different CFEE concentrations was examined (Figure 3). Swarming circles of the tested bacterial strains were assessed on soft agar plates containing 50, 100, and $200 \mu \mathrm{g} / \mathrm{mL}$ CFEE, respectively; diameters of the swarming circles are shown in Table 2. The diameter of planktonic circle produced by $E$. coli K-12 was $9.02 \mathrm{~cm}$ in diameter and covered the entire surface of the plates in the absence of CFEE. However, with increasing CFEE concentrations, the diameter of this planktonic circle decreased significantly $(p<0.05)$. The inhibition rate was up to $90.80 \%$ with $200 \mu \mathrm{g} / \mathrm{mL}$ CFEE. In the absence of CFEE, the diameter of planktonic circle formed by P. aeruginosa PAO1 was $4.61 \mathrm{~cm}$ in diameter, and this diameter also decreased with increasing CFEE concentrations. The inhibition rate of swarming circle diameters in P. aeruginosa PAO1 was up to $88.94 \%$ with $200 \mu \mathrm{g} / \mathrm{mL}$ CFEE. Therefore, CFEE can interfere with the swarming abilities of both E. coli K-12 and P. aeruginosa PAO1 without affecting their growth, but the two strains show different degrees of QS interference by CFEE. This result is the same as we previously reported for polyphenols of Rosa rugosa [24], and is also consistent with the report by Liu et al. on naringin extract [30]. It is likely that the chemical compositions of extracts from different plants are not identical and may contain different types of polyphenols. Thus, the QSI activities of different extracts may vary, even to the same bacterial strain/species.
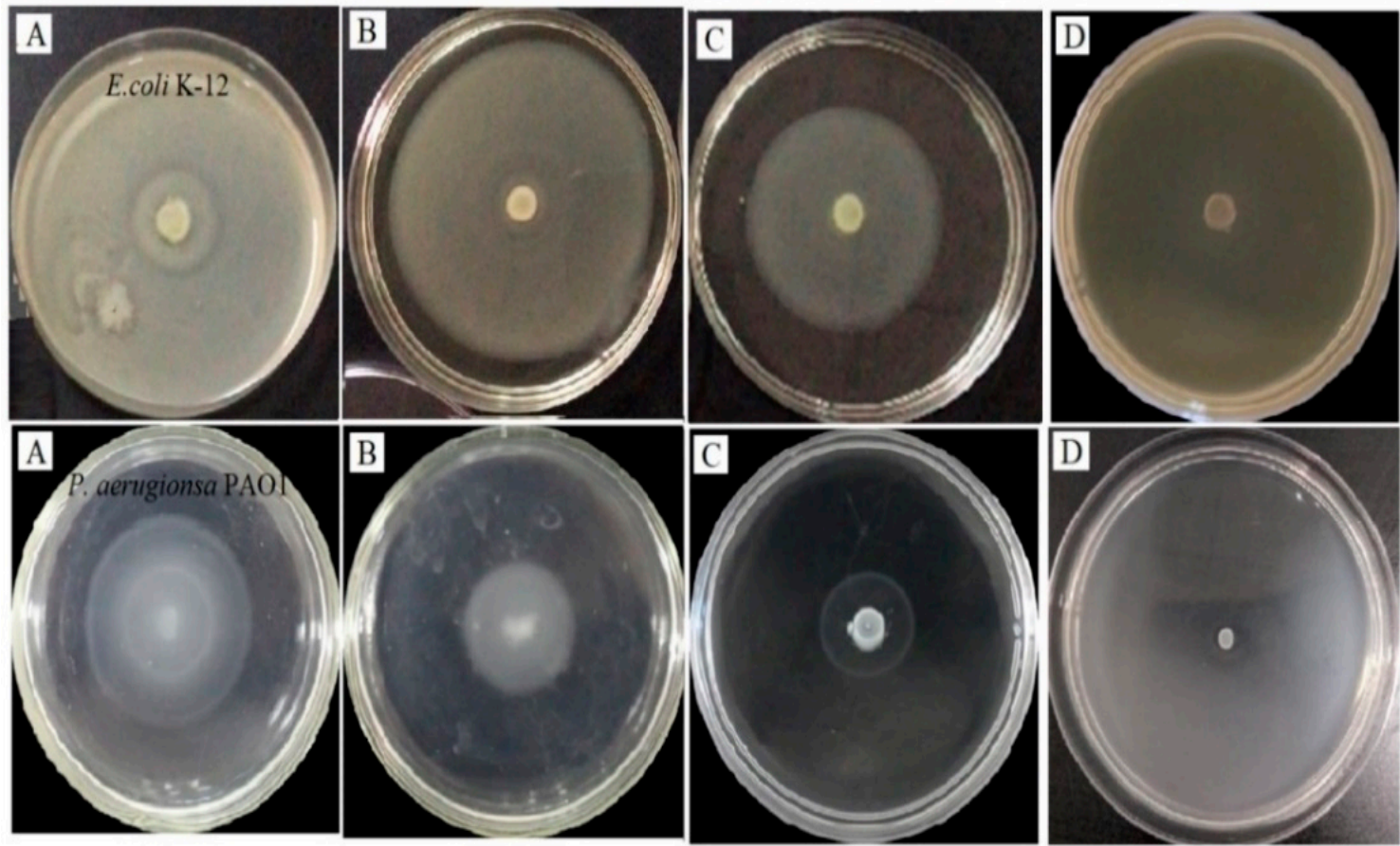

Figure 3. CFEE affected on migration distance of E. coli K-12 and P. aerugionsa PAO1: (A), CK; (B), $50 \mu \mathrm{g} / \mathrm{mL}$ of CFEE; (C), $100 \mu \mathrm{g} / \mathrm{mL}$ of CFEE; (D), $200 \mu \mathrm{g} / \mathrm{mL}$ of CFEE. 
Table 2. Inhibition rates of planktonic circle by different concentrations of CFEE.

\begin{tabular}{ccccccc}
\hline \multirow{2}{*}{$\begin{array}{c}\text { CFEE } \\
\text { Concentration }\end{array}$} & $\begin{array}{c}\text { Diameter } \\
\mathbf{( m m )}\end{array}$ & $\begin{array}{c}\text { Inhibited } \\
\text { Rate } \mathbf{( \% )}\end{array}$ & $\begin{array}{c}\text { Diameter } \\
\mathbf{( m m )}\end{array}$ & $\begin{array}{c}\text { Inhibited } \\
\text { Rate (\%) }\end{array}$ & $\begin{array}{c}\text { Diameter } \\
\mathbf{( m m )}\end{array}$ & $\begin{array}{c}\text { Inhibited } \\
\text { Rate (\%) }\end{array}$ \\
\hline E. coli $\mathrm{K}-12$ & $75.4 \pm 0.8$ & 16.41 & $50.7 \pm 1.3$ & 43.79 & $8.3 \pm 0.3$ & 90.80 \\
P. aerugionsa PAO1 & $28.7 \pm 1.1$ & 37.74 & $26.5 \pm 0.2$ & 42.52 & $5.1 \pm 0.1$ & 88.94 \\
\hline
\end{tabular}

\subsection{CFEE Interrupts Biofilm Formation in Tested Strains}

It is generally accepted that the biofilm formation of C. violaceum 026 , E. coli K-12, and P. aeruginosa PAO1 are regulated by the QS system. To further verify the QSI activity of CFEE, biofilm yields of these three tested strains were determined (Figure 4).

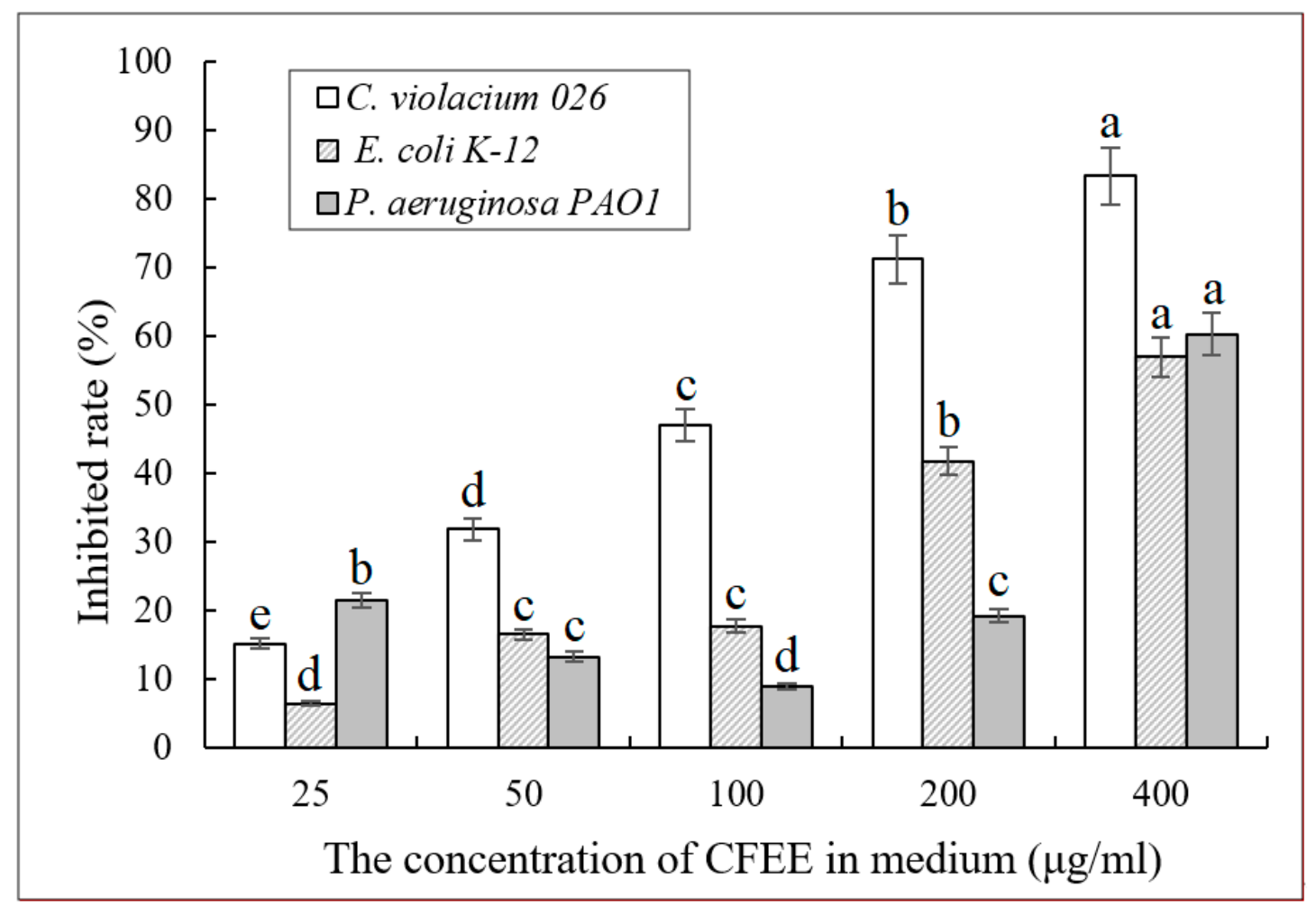

Figure 4. Inhibited rate of bacteria biofilm formation of tested strains under different concentrations of CFEE. Each bar represents the average of five measurements and their standard deviations. Different letters indicate significant differences in inhibition rates.

The total yield of the biofilms formed by $C$. violaceum 026 significantly $(0.01<p<0.05)$ decreased as the CFEE concentration increased. This indicated that CFEE could inhibit $C$. violaceum 026 biofilm formation and that the rate of inhibition was positively correlated with CFEE concentration. In $E$. coli $\mathrm{K}-12$, the total yield of biofilms did not significantly $(p>0.05)$ change with the increasing CFEE concentrations up to $100 \mu \mathrm{g} / \mathrm{mL}$. However, CFEE at concentrations greater than $100 \mu \mathrm{g} / \mathrm{mL}$ could inhibit biofilm formation by E. coli K-12. CFEE also inhibited biofilm formation by P. aeruginosa PAO1 at concentrations greater than $200 \mu \mathrm{g} / \mathrm{mL}$. In contrast with E. coli K-12, the biofilm productions formed by $P$. aeruginosa PAO1 increased significantly $(p<0.05)$ with increasing CFEE concentrations from 25 to $100 \mu \mathrm{g} / \mathrm{mL}$. These findings indicate that CFEE can interfere with the normal formation of $P$. aeruginosa PAO1 biofilms, which is regulated by the QS system. Although the amount of P. aeruginosa PAO1 biofilm increased in the presence of increasing concentrations of CFEE, the structure of the biofilm may have changed. Naringin can loosen the biofilm structure of P. aeruginosa PAO1, with an 
apparent increase in thickness of the biofilm and decrease in density, which is also a typical feature of QSI activity [30]. CFEE may therefore induce changes in the biofilm structure as observed with naringin. Consequently, the scavenging capacity of CFEE on E. coli K-12 and P. aeruginosa PAO1 biofilms was investigated.

\subsection{CFEE Scavenging Capacity on Biofilms of Tested Strains}

CFEE had a scavenging effect on mature biofilms formed by E. coli K-12 and P. aeruginosa PAO1 (Figure 5). Untreated by CFEE, mature biofilms had a higher bacterial density and were

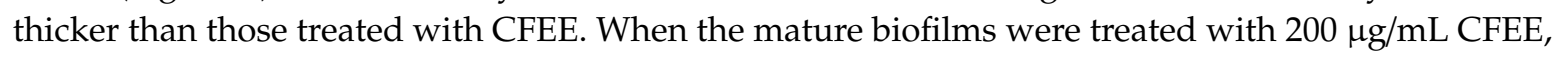
the biofilms become thin and loose. Treatment with $400 \mu \mathrm{g} / \mathrm{mL}$ CFEE almost completely destroyed all mature biofilms formed by both E. coli K-12 and P. aeruginosa PAO1. This was consistent with early measurements of biofilm productions in this text.
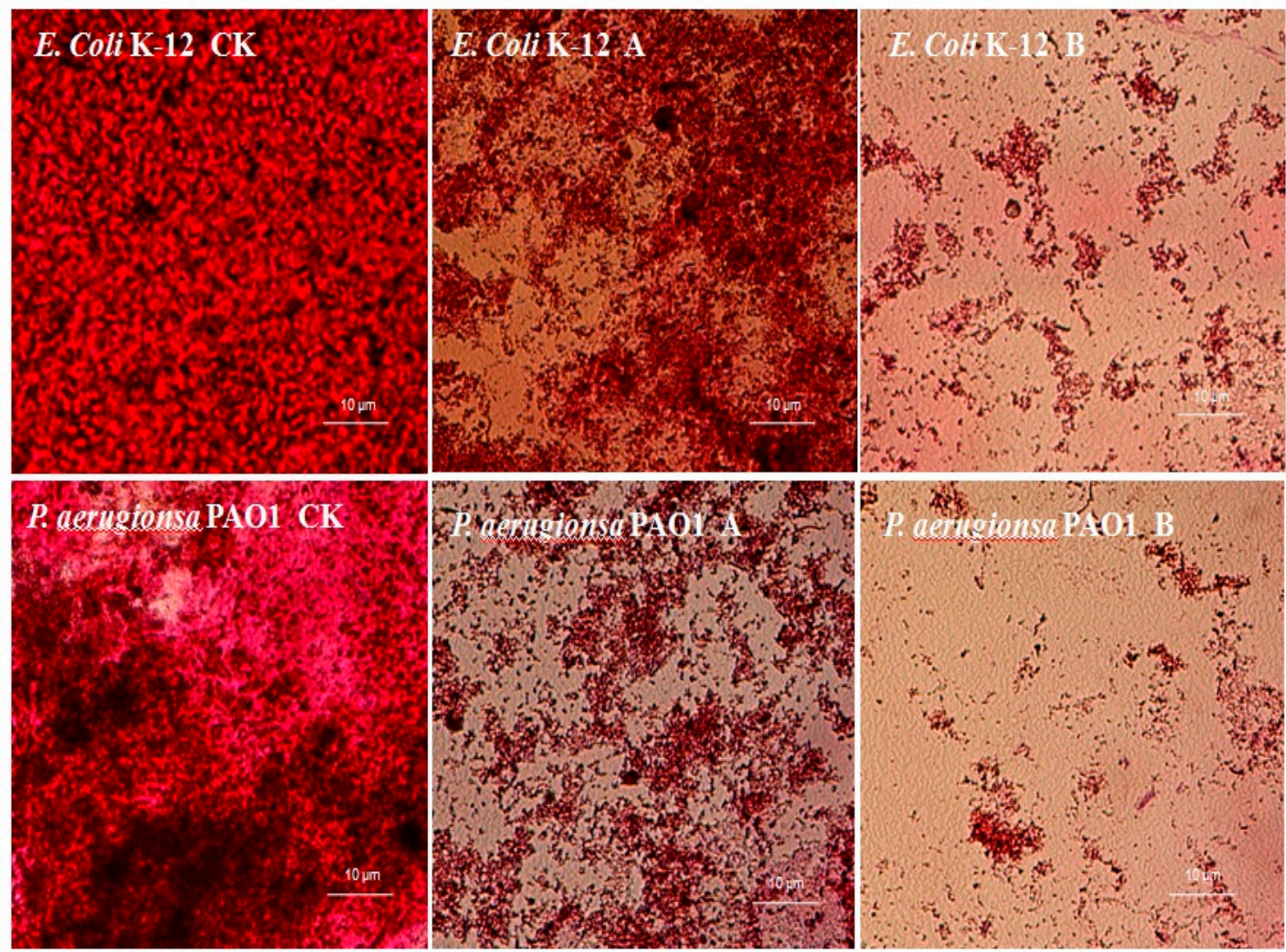

Figure 5. Scavenging effects of CFEE on mature biofilms formed by E. coli K-12 and P. aeruginosa PAO1.

(A) $200 \mu \mathrm{g} / \mathrm{mL}$; (B) $400 \mu \mathrm{g} / \mathrm{mL}$.

QS influences the initiation and maturation of bacterial biofilms [31]. CFEE inhibited biofilm formation in the tested strains and destroyed mature biofilms. This is congruent with our previous observation of Rosa rugosa polyphenols [23]. Therefore, CFEE is a potential QSI for Gram-negative bacteria, and it is worth investigating the active molecule composition and their mechanism of action.

\subsection{CFEE Chemical Composition}

The chemical composition of CFEE was determined using ultra-high performance liquid chromatography (UHPLC)-heated electrospray ionization (HESI)-tandem mass spectrometry (MS/MS). The total ion current of CFEE is shown in Figure 6, and each peak was assigned a number. In the negative mode, 23 peaks were detected. The acquired raw data were analyzed using Compound Discover 3.2 with the metabolite databasemz, and revealed 21 compounds corresponding to 21 chromatographic 
peaks, respectively. Furthermore, the molecular weights of chromatographic peaks 2 and 10 could be accurately displayed, but the comparison results of the fragment ion information in the database could not infer the compounds.

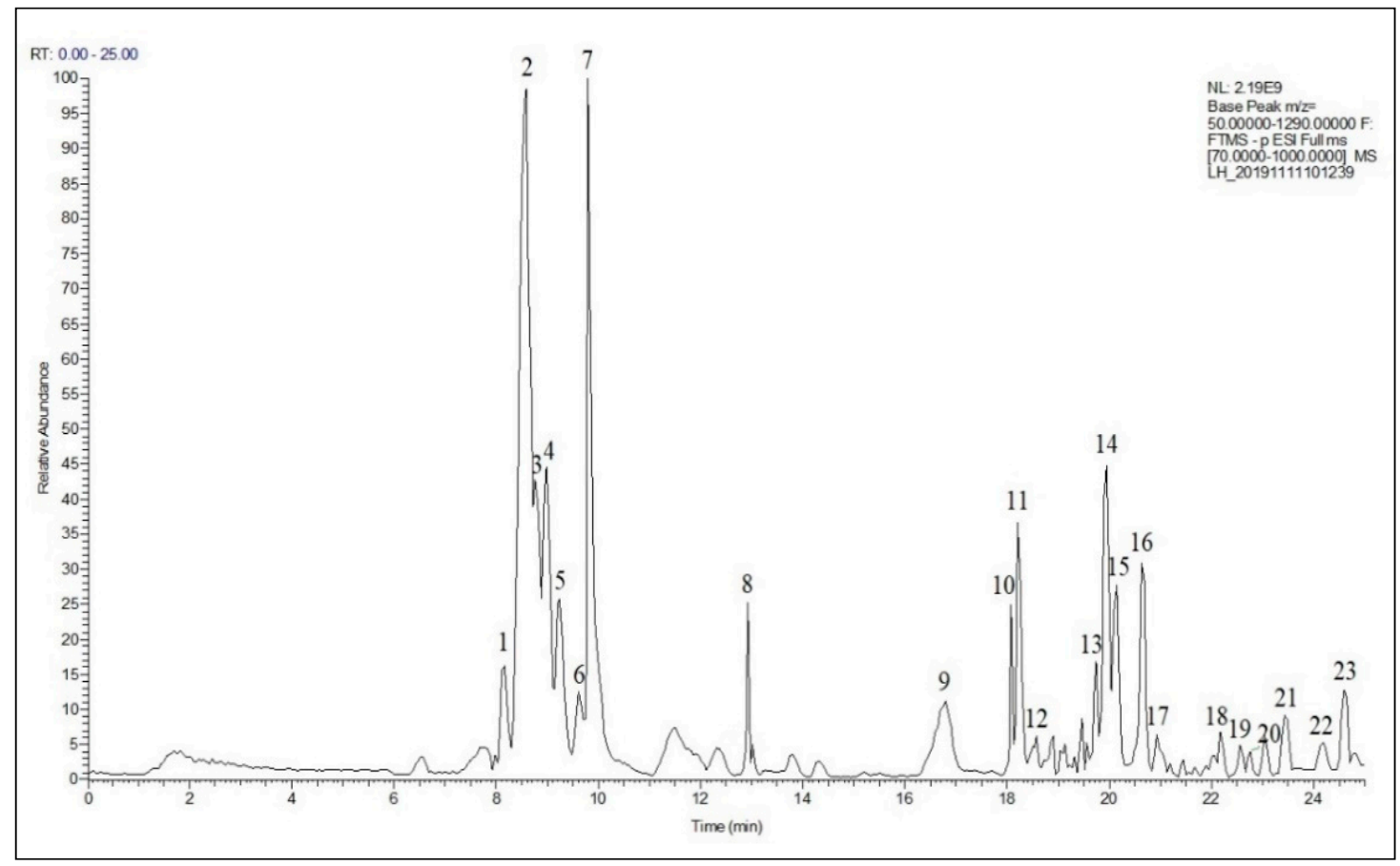

Figure 6. The total ion current of CFEE identified by UHPLC-HESI-MS/MS.

Details of the 21 compounds identified in CFEE are displayed in Table 3 and characteristic ion fragments of compounds confirmed from each peak are presented in the Supplementary Material (Figures of $\mathrm{MS}^{1-}$ and the fragment ion composition of $\mathrm{MS}^{2-}$ ). Organic acids are one of the principal components of CFEE, with four typical organic acids- quinic acid, glyceric acid, malic acid, and succinic acid corresponding to peaks 4, 6, 7, and 9, respectively. The relative content of these four acids comprise $46.503 \%$ of the total of 23 peaks. Additionally, CFEE contains citric acid and a small amount of salicylic acid. Verbascoside (Peak 14), the relative content of which reaches up to $26.438 \%$, is the main polyphenol in CFEE. Further investigation on the QSI activity of this component is recommended for future studies. CFEE also contains kinds of phenolic acid compounds, including caffeic acid, gallic acid, ferulic acid, coumaric acid, and isophthalic acid. Caffeic acid is one of the principal CFEE components, and has previously been reported to be a QSI [32].

While most of the phenolic acid compounds in CFEE have previously been reported to be AI-1 type QSIs [15], QSI activities of organic acids have rarely been reported. Organic acids are one of the principal components of CFEE and are important raw materials used in the food, medicine, and chemical industries. Therefore, organic acids were selected for further analysis and identification of potential new QSIs.

Table 3. The compounds in CFEE as identified by UHPLC-HESI-MS/MS.

\begin{tabular}{cccccccc}
\hline Peak No. & RT (min) & $\begin{array}{c}\text { Molecular } \\
\text { Weight }\end{array}$ & $\begin{array}{c}\text { Molecular } \\
\text { Formula }\end{array}$ & $\begin{array}{c}\Delta \text { mass } \\
(\mathbf{p p m})\end{array}$ & $\begin{array}{c}\text { Tentative Identification } \\
\text { maVault }\end{array}$ & $\begin{array}{c}\text { Content } \\
\text { (\%A Area) }\end{array}$ \\
\hline 1 & 8.154 & 132.05 & $\mathrm{C}_{4} \mathrm{H}_{8} \mathrm{~N}_{2} \mathrm{O}_{3}$ & -10 & Asparagine & 95.9 & 0.620 \\
2 & 8.585 & 208.06 & $\mathrm{C}_{4} \mathrm{H}_{4} \mathrm{~N}_{10} \mathrm{O}$ & - & Unknown & - & 0.129 \\
3 & 8.628 & 194.04 & $\mathrm{C}_{6} \mathrm{H}_{10} \mathrm{O}_{7}$ & -3.41 & Glucuronic acid & 64.0 & 7.467 \\
4 & 8.973 & 192.06 & $\mathrm{C}_{7} \mathrm{H}_{12} \mathrm{O}_{6}$ & -5.03 & Quinic acid & 91.8 & 15.090 \\
5 & 9.017 & 192.03 & $\mathrm{C}_{6} \mathrm{H}_{8} \mathrm{O}_{7}$ & -2.91 & Citric acid & 94.0 & 2.739 \\
\hline
\end{tabular}


Table 3. Cont.

\begin{tabular}{|c|c|c|c|c|c|c|c|}
\hline Peak No. & RT (min) & $\begin{array}{c}\text { Molecular } \\
\text { Weight }\end{array}$ & $\begin{array}{l}\text { Molecular } \\
\text { Formula }\end{array}$ & $\begin{array}{l}\Delta \text { mass } \\
(\mathrm{ppm})\end{array}$ & Tentative Identification & $\begin{array}{c}\text { mzVault } \\
\text { Match }\end{array}$ & $\begin{array}{l}\text { Content } \\
\text { (\%Area) }\end{array}$ \\
\hline 6 & 9.237 & 106.03 & $\mathrm{C}_{3} \mathrm{H}_{6} \mathrm{O}_{4}$ & -14.31 & Glyceric acid & 87.3 & 7.502 \\
\hline 7 & 9.785 & 134.02 & $\mathrm{C}_{4} \mathrm{HO}_{5}$ & -10.1 & Malic acid * & 97.0 & 16.948 \\
\hline 8 & 12.925 & 261.08 & $\mathrm{C}_{10} \mathrm{H}_{15} \mathrm{NO}_{7}$ & - & Hymexazol O-glucoside & - & 0.021 \\
\hline 9 & 16.739 & 118.03 & $\mathrm{C}_{4} \mathrm{H}_{6} \mathrm{O}_{4}$ & -4.27 & Succinic acid * & 96.2 & 6.964 \\
\hline 10 & 18.071 & - & - & - & Unknown & - & 0.198 \\
\hline 11 & 18.204 & 316.08 & $\mathrm{C}_{13} \mathrm{H}_{16} \mathrm{O}_{9}$ & 2.96 & NP-020139 & 67.0 & 0.246 \\
\hline 12 & 18.617 & 170.02 & $\mathrm{C}_{7} \mathrm{H}_{6} \mathrm{O}_{5}$ & -6.16 & Gallic acid & - & 0.167 \\
\hline 13 & 19.742 & 356.11 & $\mathrm{C}_{16} \mathrm{H}_{20} \mathrm{O}_{9}$ & UN & Gentiopicrin & 73.9 & 0.124 \\
\hline 14 & 19.939 & 624.20 & $\mathrm{C}_{29} \mathrm{H}_{36} \mathrm{O}_{15}$ & -1.88 & Verbascoside & 92.1 & 26.438 \\
\hline 15 & 20.134 & 166.03 & $\mathrm{C}_{8} \mathrm{H}_{6} \mathrm{O}_{4}$ & -6.89 & Isophthailc acid & 81.5 & 0.190 \\
\hline 16 & 20.622 & 180.04 & $\mathrm{C}_{9} \mathrm{H}_{8} \mathrm{O}_{4}$ & -5.39 & Caffeic acid * & 94.0 & 6.377 \\
\hline 17 & 20.924 & 138.03 & $\mathrm{C}_{7} \mathrm{H}_{6} \mathrm{O}_{3}$ & -9.31 & Salicylic acid & 86.3 & 1.414 \\
\hline 18 & 22.163 & 164.05 & $\mathrm{C}_{9} \mathrm{H}_{8} \mathrm{O}_{3}$ & -0.14 & Coumaric acid & 79.4 & 1.260 \\
\hline 19 & 22.543 & 194.06 & $\mathrm{C}_{10} \mathrm{H}_{10} \mathrm{O}_{4}$ & -3.42 & Ferulic acid & 94.7 & 1.276 \\
\hline 20 & 22.706 & 164.05 & $\mathrm{C}_{9} \mathrm{H}_{8} \mathrm{O}_{3}$ & -6.5 & Coumaric acid & 91.6 & 0.309 \\
\hline 21 & 23.477 & 146.04 & $\mathrm{C}_{9} \mathrm{H}_{6} \mathrm{O}_{2}$ & - & Coumarin & 57.9 & 0.778 \\
\hline 22 & 24.275 & 145.05 & $\mathrm{C}_{9} \mathrm{H}_{7} \mathrm{NO}$ & -8.84 & 4-Indolecarbaldehyde & 77.4 & 0.207 \\
\hline 23 & 24.591 & 328.22 & $\mathrm{C}_{18} \mathrm{H}_{32} \mathrm{O}_{5}$ & -2.74 & Corchorifatty acid & 89.4 & 3.537 \\
\hline
\end{tabular}

\subsection{QSI Activities of Malic Acid and Succinic Acid}

Malic acid and succinic acid are two very cheap and readily available organic acids. Therefore, the MIC and anti-QS activities of these two compounds were directly tested. The MIC of succinic acid and malic acid in C. violaceum 026 were 1200 and $800 \mu \mathrm{g} / \mathrm{mL}$, respectively. Anti-QS activities of the two compounds were tested at concentrations lower than $800 \mu \mathrm{g} / \mathrm{mL}$ (Figure 7). Non-purple rings appeared around the filter papers loaded with malic acid and succinic acid, indicating that violacein production was inhibited. The anti-violacein circle diameters of CFEE (Figure 7B, 1), malic acid (Figure 7B, 2) and succinic acid (Figure 7B, 3) were $1.89 \pm 0.16 \mathrm{~cm}, 3.06 \pm 0.11 \mathrm{~cm}, 4.67 \pm 0.23 \mathrm{~cm}$, respectively. This suggested that the QSI activities of malic acid and succinic acid were stronger than that of CFEE, with succinic acid displaying the strongest QSI activity. These findings indicate that CFEE-mediated inhibition of violacein production is due to the polyphenol, malic acid, and succinic acid contents of CFEE.

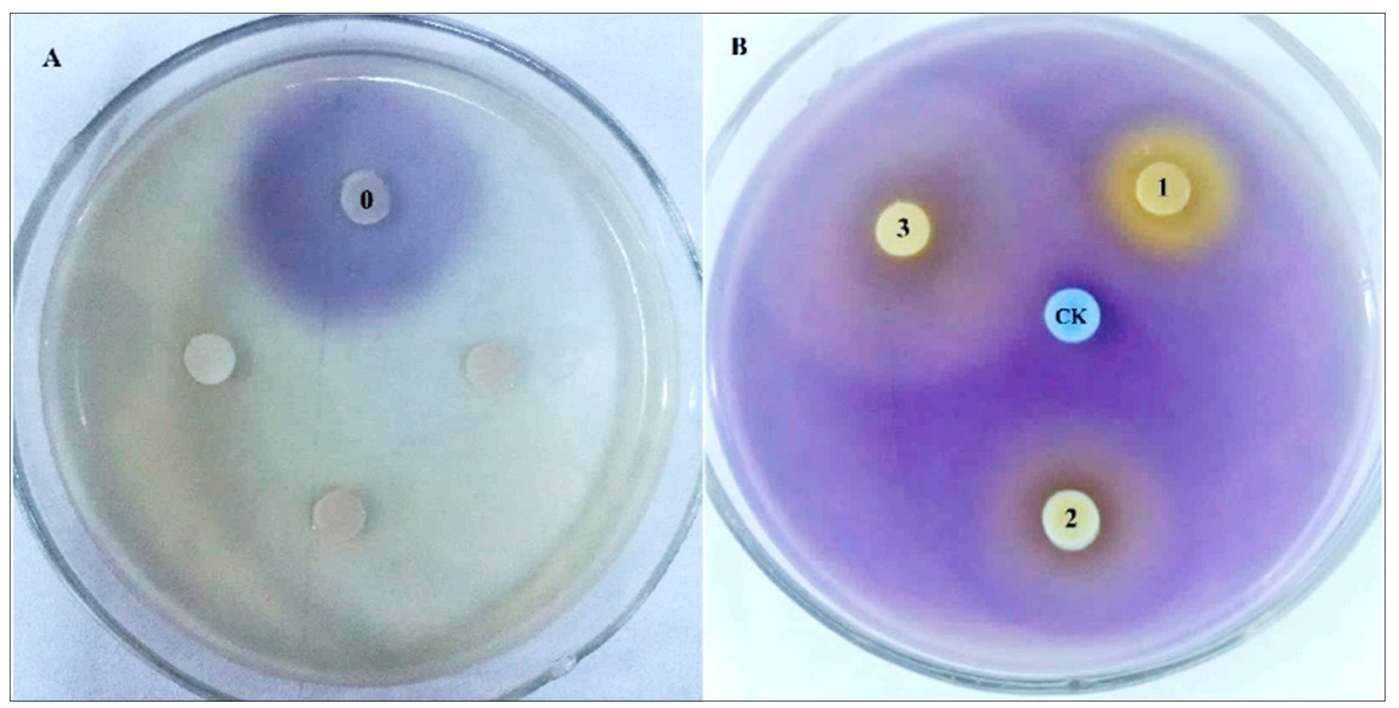

Figure 7. QSI activity of crude C. grandiflora flower extract and CFEE identified by report plates. (A) LB agar plate incubated by $C$. violaceum 026 ; (B) LB agar plate supplemented by $\mathrm{C}_{6}-\mathrm{HSL}$ and incubated by C. violaceum 026; “CK", methanol as negative control; “0", $\mathrm{C}_{6}$-HSL; "1", CFEE; "2", $200 \mu \mathrm{g} / \mathrm{mL}$ succinic acid; "3", $200 \mu \mathrm{g} / \mathrm{mL}$ malic acid. 
UPLC-MS/MS results in this study revealed that organic acids are one of the principal components of CFEE. None of these organic acids have been reported to have QSI activity, except malic acid which has been reported to have inhibitory effect on AI-2 QS system of E. coli O157:H7 and S. typhimurium [33]. Our results demonstrate for the first time that malic acid and succinic acid have inhibitory effects on the AI-1 QS system of C. violaceum 026. Therefore, malic acid and succinic acid may play major roles in the QSI activities of CFEE and could have potential value as antibacterial compounds.

\section{Materials and Methods}

\subsection{Materials, Test Strains, Culture Media, and Growth Conditions}

C. violaceum 026 is a kanamycin resistant double mini-Tn5 mutant of C. violaceum ATCC 12472, it can't synthesize its own C6-HSL, but can respond to $\mathrm{C}_{4}$-AHL or $\mathrm{C}_{6}$-AHL to produce violacein. It was kindly provided by Professor Robert J. C. (Texas State University, San Marcos, TX, USA). C. violaceum 026 was routinely cultured aerobically in Luria-Bertani (LB) medium (1\% tryptone, $0.5 \%$ yeast extract, $0.5 \% \mathrm{NaCl})$ supplemented with $20 \mu \mathrm{g} / \mathrm{mL}$ kanamycin in a shaking incubator $(120 \mathrm{rpm})$ at $28{ }^{\circ} \mathrm{C}$. P. aeruginosa PAO1 test organism was purchased from Fisheries Research Institute (Shanghai, China). E. coli K-12 was supplied by Nanjing Center for Disease Control and Prevention (Nanjing, China). $P$. aeruginosa PAO1 and E. coli K-12 were used to determine the biofilm formation and were cultivated in LB medium at $37^{\circ} \mathrm{C}$ without shaking.

Dried flowers (Chinese herb source) used in this study were all purchased from Zhang zhongjing pharmacy (Kaifeng, China).

\subsection{Crude Extract Preparation from the Chinese Herbal Medicines}

Dried samples were pulverized with a mortar. Dry powder ( $5 \mathrm{~g}$ ) was dissolved in $80 \%$ ethanol and treated by an assistant of intermittent ultrasound. The samples were treated by ultrasound intermittently for $60 \mathrm{~min}$, and the supernatant was placed in a $10 \mathrm{~mL}$ centrifuge tube and was centrifuged at $4{ }^{\circ} \mathrm{C}, 4024 \times g$ for $20 \mathrm{~min}$. The resulting supernatant was distilled to dry using a rotary evaporator, redissolved in $1 \mathrm{~mL}$ methanol, and filtered using an aseptic filter. All samples were stored at $-4{ }^{\circ} \mathrm{C}$ until use in subsequent experiments.

\subsection{Screening for QSIS}

C. violaceum 026 was activated in $5 \mathrm{~mL}$ fresh $\mathrm{LB}$ medium and cultured at $28{ }^{\circ} \mathrm{C}$ for $24 \mathrm{~h}$. This suspension was added to fresh LB medium containing $0.85 \%$ agar, and kanamycin was added to a final concentration of $20 \mu \mathrm{g} / \mathrm{mL}$. Next, $50 \mu \mathrm{L} \mathrm{C6-HSLs} \mathrm{(40} \mathrm{nmol/L),} \mathrm{used} \mathrm{as} \mathrm{exogenous} \mathrm{signal}$ molecules, was coated on the surface of the solidified medium. The agar plates without $\mathrm{C}_{6}$-HSLs were used as negative controls. The testing sample $(20 \mu \mathrm{L})$ was pipetted onto sterile paper discs $(6 \mathrm{~mm})$. These disks were placed on the solidified agar plates and $20 \mu \mathrm{L}$ sterile methanol was used as a negative control. The reporter plates were incubated at $28^{\circ} \mathrm{C}$ for $1-2$ days.

\subsection{CFEE Preparation}

CFEE was prepared according to a previously report with slight modifications [23]. Polar macroporous resin was selected as the preparation filler because of the strong polarity of organic acid and polyphenols. The crude C. grandiflora extract was filtered, diluted with deionized water, and applied to the glass column $(17 \times 300 \mathrm{~mm})$ containing activated macroporous resin HPD600 (Qinshi Technology Ltd., Zhengzhou, China). The column was washed with deionized water (200 mL) to remove impurities, and the CFEE was eluted using $80 \%$ ethanol with a flow rate of $1 \mathrm{~mL} / \mathrm{min}$. The solvent was removed by rotary evaporator and the CFEE was re-dissolved in deionized water. The CFEE sample was then lyophilized (at $108 \pm 5 \mathrm{~Pa}$ chamber pressure and $-38 \pm 1^{\circ} \mathrm{C}$ cold collector temperature after pre-freezing at $-20{ }^{\circ} \mathrm{C}$ for $24 \mathrm{~h}$ ), and stored at $-20{ }^{\circ} \mathrm{C}$ for further experiments. Lyophilized material was re-dissolved in methanol before use in experiments. 


\subsection{Determination of Total Polyphenol Content of CFEE}

The total polyphenol concentration was analyzed using the previously described Folin-Ciocalteu method [34]. CFEE $(1 \mathrm{~mL}, 100 \mu \mathrm{g} / \mathrm{mL})$ was mixed with Folin-Ciocalteu reagent $(1 \mathrm{M}, 0.5 \mathrm{~mL})$ for $3 \mathrm{~min}$, then $3 \mathrm{~mL}$ of $7.5 \% \mathrm{Na}_{2} \mathrm{CO}_{3}$ was added and the mixture was allowed to react for $2 \mathrm{~h}$ with intermittent mixing. The absorbance of the mixture was measured at $750 \mathrm{~nm}$ using a U-3210 spectrophotometer (Hitachi, Tokyo, Japan). A standard curve, using gallic acid (methanol solution), was prepared using the same method.

\subsection{Determination of the MIC of CFEE}

MIC is defined as the lowest concentration which showed inhibition of visible growth of the tested bacterial strains [35]. The MIC of CFEE was determined against the tested bacterial strains using the broth macrodilution method as recommended by the Clinical and Laboratory Standards Institute, USA (2006). Bacterial strains were inoculated into $20 \mathrm{~mL} \mathrm{LB}$ medium supplemented with diluted extracts at final concentrations ranging from 0.1 to $2.0 \mathrm{mg} / \mathrm{mL}$, and were incubated at their optimum culture temperature for $24 \mathrm{~h}$. The absorbance of the media before and after incubation was measured at $600 \mathrm{~nm}$ using a spectrophotometer. Sub-MIC concentrations were selected for anti-biofilm and anti-QS activity analyses.

\subsection{QSI Assay}

C. violaceum 026 was used as a reporter strain to measure the QSI activity of CFEE as previously reported [23]. C. violaceum 026 was inoculated into $4 \mathrm{~mL} \mathrm{LB}$ medium and incubated for $18 \mathrm{~h}$ at $28^{\circ} \mathrm{C}$. The culture was diluted 1:50 into $4 \mathrm{~mL}$ fresh LB medium containing $40 \mathrm{nM}$ C6-HSL and CFEE $(25,50,100,200$, and $400 \mu \mathrm{g} / \mathrm{mL})$ and was incubated for $48 \mathrm{~h}$ at $28^{\circ} \mathrm{C}$. A sample without CFEE was used as a control. Cultures were vortexed to resuspend any adherent cells, and $300 \mu \mathrm{L}$ was placed in a $1.5 \mathrm{~mL}$ microtube. Cells were lysed by adding $150 \mu \mathrm{L}$ of $10 \%$ sodium dodecyl sulfate (SDS), followed by vortexing for $10 \mathrm{~s}$. Violacein was extracted from the cell lysate by adding $600 \mu \mathrm{L}$ water-saturated butanol, vortexing for $5 \mathrm{~s}$, and centrifuging at $1611 \times g$ for $5 \mathrm{~min}$. The butanol phase (upper layer) containing violacein was transferred into 96-well microtiter plates, with $150 \mu \mathrm{L}$ per well. The absorbance of the extract was measured at $595 \mathrm{~nm}$ using a microplate reader (Bio Tek, Winooski, VT, USA). The effects of CFEE were evaluated based on relative violacein production levels, with the control value set to $100 \%$. All experiments were performed in triplicate, and data are presented as means \pm standard deviation.

\subsection{Swarming Motility Inhibition Assay}

Swarming motility assays were performed as previously reported [36]. Briefly, $5 \mathrm{~mL}$ molten soft-top LB medium (containing 0.3\% agar) was mixed with CFEE at final concentrations of 50, 100, and $200 \mu \mathrm{g} / \mathrm{mL}$, respectively. These mixtures were immediately overlaid on solidified LB agar plates. Once the overlaid agar had solidified, prepared pathogen strains were applied to the center of the plate using an inoculation needle and were then cultivated at $37^{\circ} \mathrm{C}$ for $30 \mathrm{~h}$. Swarming migrations were observed and migration distances of C. violaceum 026 , E. coli K-12, and P. aeruginosa PAO1 were measured. All experiments were performed in triplicate, and data are presented as means \pm standard deviation.

\subsection{Biofilm Formation Inhibition Assay}

Biofilm formation of the studied strains was determined as described previously [37], with some modifications. A total of $600 \mu \mathrm{L}$ LB medium containing different concentrations of CFEE $(0,25,50$, 100,200 , and $400 \mu \mathrm{g} / \mathrm{mL}$ ) was added into a small glass tube, inoculated with $6 \mu \mathrm{L}$ bacterial strain, and incubated at $37^{\circ} \mathrm{C}$ for $72 \mathrm{~h}$. After incubation, the medium in each tube was gently removed with a pipette, and each tube was washed three times with $1 \mathrm{~mL}$ distilled water to remove unattached bacteria. Biofilm cells were then stained with crystal violet for $30 \mathrm{~min}$. Excess dye was removed 
with deionized water and the crystal violet adsorbed by biofilm cells was eluted with a mixture of ethanol and acetone (2:1), and the OD590 of the eluant was measured. Differences in biofilm formation were analyzed by one-way analysis of variance (ANOVA) followed by Tukey's pairwise post-hoc comparisons.

\subsection{Determination of the Scavenging Capacity of CFEE on the Mature Biofilms}

Overnight cultures of tested bacterial strains incubated in LB medium were diluted to a final density of $1.0 \times 10^{6} \mathrm{CFU} / \mathrm{mL}$ with fresh media, and $1 \mathrm{~mL}$ was dispensed into each well of a 24-well microtiter plate together with a piece of coverslip with $0.2 \mathrm{~mm}$ thick and $13 \mathrm{~mm}$ diameter (Nunc, Roskilde, Denmark). Plates were statically incubated at $37^{\circ} \mathrm{C}$ for $72 \mathrm{~h}$. Coverslips with a mature biofilm of tested strains were then placed in LB medium supplemented with 200 or $400 \mu \mathrm{g} / \mathrm{mL}$ CFEE and statically incubated at $37^{\circ} \mathrm{C}$ for $24 \mathrm{~h}$. A group of bacteria without CFEE was used as a negative control. Coverslips were then gently washed with sterile distilled water, stained with safranine, and observed and photographed using a microscopic imaging system.

\subsection{CFEE Components Assay by UHPLC-MS/MS}

Individual phenolic composition analyses were carried out by UHPLC-MS/MS analysis using a $Q$ Exactive Plus mass spectrometer (Thermo Fisher, Waltham, MN, USA) coupled with the vanquish-flex with a Hypersil GOLD column $(2.1 \times 100 \mathrm{~mm}$, with $1.9 \mu \mathrm{m}$ coating layer) (Thermo Fisher, Waltham, $\mathrm{MN}$, USA). One microliter of sample was loaded, and the temperature of the column box was set to $30{ }^{\circ} \mathrm{C}$. According to our previous report [38], the mobile phase was A: $\mathrm{HPLC}$ grade $\mathrm{H}_{2} \mathrm{O}(0.1 \%$ formic acid); B: HPLC grade acetonitrile. The chromatographic separation program was: $10 \%$ acetonitrile elution for $2 \mathrm{~min}$, then was increased to $50 \%$ within $5 \mathrm{~min}$ and maintained for $3 \mathrm{~min}$, then was increased to $80 \%$ within $10 \mathrm{~min}$, and finally increased to $100 \%$ within $5 \mathrm{~min}$. The flow rate was $0.3 \mathrm{~mL} / \mathrm{min}$.

The mass spectrometer was operated in full scan of positive and negative mode in a range of $\mathrm{m} / \mathrm{z}$ : 70-1050. The resolution of MS data was set at 70,000; the spray voltage was set at $3.2 \mathrm{kV}$ for negative mode; the capillary temperature was set at $320^{\circ} \mathrm{C}$; the auxiliary gas heater temperature was $350{ }^{\circ} \mathrm{C}$; the sheath gas flow rate was 35 units; the auxiliary gas flow was set at 15 units; the S-lens RF level was 50; the AGC target was 1e6; the maximum injection time used was $100 \mathrm{~ms}$; and the resolution of MS/MS acquisition was set at 17,500. The top eight ions in each full scan were isolated with a $1.0 \mathrm{Da}$ window, fragmented with a stepwise collision energy of 20,40 and 60 units, and a maximum injection time of $50 \mathrm{~ms}$ with an AGC target of 2e5. The acquired raw data were analyzed using Compound Discover 3.2 (Thermo Fisher, Waltham, MN, USA) with the metabolite database (mzCloud, mzVault, Masslists, and Chemspider).

\subsection{Statistical Evaluations}

Vegetative growth curves of the wild-type and mutant strains were generated by plotting the average outcomes (OD600) of three experiments per strain. Differences in biofilm formation were analyzed by one-way analysis of variance (ANOVA) followed by Tukey's pairwise post hoc comparisons.

\section{Conclusions}

At present, many kinds of natural compounds have been studied to use as new sources of QSIs. Chinese herbs have attracted much attention because of their safety and affordability. A screen of 18 different Chinese herbs for QSI active substances found that, the alcohol extract of C. grandiflora flower had strong QSI activity. CFEE could inhibit the yields of violacein produced by $C$. violaceum 026 in a dose-dependent manner. It also inhibited biofilm production by C. violaceum 026 and E. coli $\mathrm{K}-12$, and the rate of inhibition positively correlated with CFEE concentration. CFEE could also inhibit biofilm formation of P. aeruginosa PAO1 at concentrations greater than $200 \mu \mathrm{g} / \mathrm{mL}$. But it is interesting that CFEE significantly increased the biofilm production of P. aeruginosa PAO1 $(p<0.05)$, in a concentration-dependent manner $(25$ to $100 \mu \mathrm{g} / \mathrm{mL}$ ). Although the amount of P. aeruginosa PAO1 
biofilm increased in the presence of CFEE, the structure of the biofilm changed and became loose. These results show that CFEE can interfere with the normal biofilms formation of the test strains, and can also destroy the mature biofilms of E. coli K-12 and P. aeruginosa PAO1, indicating that CFEE was a potential QSI that could be considered for medicinal development as a novel antimicrobial agent.

To investigate and identify the active QSI active compounds in CFEE, UPLC-MS/MS was used to determine the composition of CFEE. CFEE contains numerous phenolic acids, such as caffeic acid, gallic acid, ferulic acid, coumaric acid and isophthalic acid, and most of these compounds have previously been reported to be AI-1 type QSIs. Meanwhile, CFEE also contains many organic acids, including malic acid, quinic acid, and succinic acid, whose relative content comprise $46.503 \%$ of the total 23 compounds. Additionally, citric acid and a small amount of salicylic acid are present in CFEE. QSI activities have not been reported for any of these organic acids with the exception of malic acid, which has an inhibitory effect on AI-2 QS of E. coli O157:H7 and S. typhimurium. Our experiments demonstrated that malic acid and succinic acid were excellent AI-1 QSIs. These two organic acids may play a major role in the QSI activities of CFEE. Future research on malic acid and succinic acid will explore their molecular mechanisms and the targets of their anti-QS effects. In summary, CFEE and its malic acid and succinic acid components are potential QSIs that could be used to develop new therapeutics targeting Gram-negative bacteria.

Supplementary Materials: The Supplementary Materials are available online. Figures S1-S23: Primary and secondary mass spectrograms of the peaks numbered in Figure 6.

Author Contributions: First author J.Z. designed the experiments, drafted the manuscript and revised the paper. F.X. helped to design some experiments and carried out the experiments. L.Y. and L.W. done a lot of screening task and photographing and sorting work of experimental pictures. M.W. participated in the design of experimental scheme and the collection and processing of experimental data. G.W. is the funding recipients and is responsible for the supervision and the entire project administration. All authors have read and agreed to the published version of the manuscript.

Funding: This research was funded by the National Nature Science Foundation of China (NSFC) (31701831) and Henan Province Science and Technology Development Project (182300410060).

Acknowledgments: The authors would like to thank the Microbiology Research Group of Nanjing Agricultural University for the donation of experimental strains and assistance with figures.

Conflicts of Interest: The authors declare no conflict of interest. The funders had no role in the design of the study; in the collection, analyses, or interpretation of data; in the writing of the manuscript, or in the decision to publish the results.

\section{References}

1. Defoirdt, T. Quorum-Sensing Systems as Targets for Antivirulence Therapy. Trends Microbiol. 2018, 26,313-328. [CrossRef] [PubMed]

2. Hancock, R.E.W. Collateral damage. Nat. Biotechnol. 2014, 32, 66-68. [CrossRef] [PubMed]

3. Wan, T.; Liu, Z.-M.; Li, L.; Leitch, A.R.; Leitch, A.R.; Lohaus, R.; Liu, Z.-J.; Xin, H.-P.; Gong, Y.-B.; Liu, Y.; et al. A genome for gnetophytes and early evolution of seed plants. Nat. Plants 2018, 4, 82-89. [CrossRef] [PubMed]

4. Yan, M.; Wang, X.; Deng, J.; Wang, L.; Cui, Z.; Shi, Z. DNA methylation and cerebellar development, the regulation of Notch and Shh pathway. Ital. J. Zoöl. 2016, 83, 34-42. [CrossRef]

5. Song, Y.; Miao, Y.; Song, C.-P. Behind the scenes: The roles of reactive oxygen species in guard cells. New Phytol. 2013, 201, 1121-1140. [CrossRef] [PubMed]

6. Ćirić, A.; Petrović, J.; Glamočlija, J.; Ivanov, M.; Nikolić, M.; Stojković, D.; Petrović, J. Natural products as biofilm formation antagonists and regulators of quorum sensing functions: A comprehensive review update and future trends. South. Afr. J. Bot. 2019, 120, 65-80. [CrossRef]

7. Wang, H.-H.; Ye, K.-P.; Zhang, Q.-Q.; Dong, Y.; Xu, X.-L.; Zhou, G.-H. Biofilm formation of meat-borne Salmonella enterica and inhibition by the cell-free supernatant from Pseudomonas aeruginosa. Food Control 2013, 32, 650-658. [CrossRef]

8. Høiby, N.; Bjarnsholt, T.; Givskov, M.; Molin, S.; Ciofu, O. Antibiotic resistance of bacterial biofilms. Int. J. Antimicrob. Agents 2010, 35, 322-332. [CrossRef] 
9. De Kievit, T.R.; Iglewski, B.H. Bacterial Quorum Sensing in Pathogenic Relationships. Infect. Immun. 2000, 68, 4839-4849. [CrossRef]

10. Bakkiyaraj, D.; Sivasankar, C.; Pandian, S.K. Inhibition of quorum sensing regulated biofilm formation in Serratia marcescens causing nosocomial infections. Bioorganic Med. Chem. Lett. 2012, 22, 3089-3094. [CrossRef]

11. Sharif, D.I.; Gallon, J.; Smith, C.J.; Dudley, E. Quorum sensing in Cyanobacteria: N-octanoyl-homoserine lactone release and response, by the epilithic colonial cyanobacterium Gloeothece PCC6909. ISME J. 2008, 2, 1171-1182. [CrossRef] [PubMed]

12. Brindhadevi, K.; LewisOscar, F.; Mylonakis, E.; Shanmugam, S.; Verma, T.N.; Pugazhendhi, A. Biofilm and Quorum sensing mediated pathogenicity in Pseudomonas aeruginosa. Process Biochem. 2020, 96, 49-57. [CrossRef]

13. Saeki, E.K.; Kobayashi, R.K.T.; Nakazato, G. Quorum sensing system: Target to control the spread of bacterial infections. Microb. Pathog. 2020, 142, 104068. [CrossRef] [PubMed]

14. McLean, R.J.C.; Pierson, L.S.; Fuqua, C.; Iii, L.S.P. A simple screening protocol for the identification of quorum signal antagonists. J. Microbiol. Methods 2004, 58, 351-360. [CrossRef] [PubMed]

15. Kalia, V.C. Quorum sensing inhibitors: An overview. Biotechnol. Adv. 2013, 31, 224-245. [CrossRef]

16. Lu, X.-L.; Zhao, C.-H.; Yao, X.-L.; Zhang, H. Quercetin attenuates high fructose feeding-induced atherosclerosis by suppressing inflammation and apoptosis via ROS-regulated PI3K/AKT signaling pathway. Biomed. Pharmacother. 2017, 85, 658-671. [CrossRef]

17. Xue, F.; Nie, X.; Shi, J.; Liu, Q.; Wang, Z.; Li, X.; Zhou, J.; Su, J.; Xue, M.; Chen, W.-D.; et al. Quercetin Inhibits LPS-Induced Inflammation and ox-LDL-Induced Lipid Deposition. Front. Pharmacol. 2017, 8, 40. [CrossRef]

18. Liu, Y.; Li, Z.; Xue, X.; Wang, Y.; Zhang, Y.; Wang, J. Apigenin reverses lung injury and immunotoxicity in paraquat-treated mice. Int. Immunopharmacol. 2018, 65, 531-538. [CrossRef]

19. Zhong, X.; Zhang, L.; Li, Y.; Li, P.; Li, J.; Cheng, G. Kaempferol alleviates ox-LDL-induced apoptosis by up-regulation of miR-26a-5p via inhibiting TLR4/NF- $\mathrm{B}$ pathway in human endothelial cells. Biomed. Pharmacother. 2018, 108, 1783-1789. [CrossRef]

20. Bouyahya, A.; Dakka, N.; Et-Touys, A.; Abrini, J.; Bakri, Y. Medicinal plant products targeting quorum sensing for combating bacterial infections. Asian Pac. J. Trop. Med. 2017, 10, 729-743. [CrossRef]

21. Erhabor, C.; Erhabor, J.; McGaw, L. The potential of South African medicinal plants against microbial biofilm and quorum sensing of foodborne pathogens: A review. South. Afr. J. Bot. 2019, 126, 214-231. [CrossRef]

22. Li, H.; Wang, S.; Yue, Z.; Ren, X.; Xia, J. Traditional Chinese herbal injection: Current status and future perspectives. Fitoterapia 2018, 129, 249-256. [CrossRef] [PubMed]

23. Zhang, J.; Rui, X.; Wang, L.; Guan, Y.; Sun, X.; Dong, M.S. Polyphenolic extract from Rosa rugosa tea inhibits bacterial quorum sensing and biofilm formation. Food Control 2014, 42, 125-131. [CrossRef]

24. Zhang, Q.; Rui, X.; Li, W.; Chen, X.; Jiang, M.; Dong, M.S. Anti-swarming and -biofilm activities of rose phenolic extract during simulated in vitro gastrointestinal digestion. Food Control 2016, 64, 189-195. [CrossRef]

25. Packiavathy, I.A.S.V.; Agilandeswari, P.; Musthafa, K.S.; Pandian, S.K.; Ravi, A.V. Antibiofilm and quorum sensing inhibitory potential of Cuminum cyminum and its secondary metabolite methyl eugenol against Gram negative bacterial pathogens. Food Res. Int. 2012, 45, 85-92. [CrossRef]

26. Packiavathy, I.A.S.V.; Priya, S.; Pandian, S.K.; Ravi, A.V. Inhibition of biofilm development of uropathogens by curcumin-An anti-quorum sensing agent from Curcuma longa. Food Chem. 2014, 148, 453-460. [CrossRef]

27. Chusri, S.; Na Phatthalung, P.; Voravuthikunchai, S. Anti-biofilm activity of Quercus infectoria G. Olivier against methicillin-resistant Staphylococcus aureus. Lett. Appl. Microbiol. 2012, 54, 511-517. [CrossRef]

28. Truchado, P.; Bastida, J.A.G.; Larrosa, M.; Castro-Ibáñez, I.; Espín, J.C.; Tomas-Barberan, F.; García-Conesa, M.-T.; Allende, A. Inhibition of Quorum Sensing (QS) in Yersinia enterocolitica by an Orange Extract Rich in Glycosylated Flavanones. J. Agric. Food Chem. 2012, 60, 8885-8894. [CrossRef]

29. Durán, N.; Justo, G.Z.; Durán, M.; Brocchi, M.; Cordi, L.; Tasic, L.; Castro, G.R.; Nakazato, G. Advances in Chromobacterium violaceum and properties of violacein-Its main secondary metabolite: A review. Biotechnol. Adv. 2016, 34, 1030-1045. [CrossRef]

30. Liu, Z.; Pan, Y.; Li, X.; Jie, J.; Zeng, M. Chemical composition, antimicrobial and anti-quorum sensing activities of pummelo peel flavonoid extract. Ind. Crops Prod. 2017, 109, 862-868. [CrossRef] 
31. De Kievit, T.R. Quorum sensing inPseudomonas aeruginosabiofilms. Environ. Microbiol. 2009, 11, $279-288$. [CrossRef] [PubMed]

32. Borges, A.; Serra, S.; Abreu, A.C.; Saavedra, M.J.; Salgado, A.; Simões, M. Evaluation of the effects of selected phytochemicals on quorum sensing inhibition andin vitrocytotoxicity. Biofouling 2013, 30, 183-195. [CrossRef] [PubMed]

33. Almasoud, A.; Hettiarachchy, N.; Rayaprolu, S.; Babu, D.; Kwon, Y.M.; Mauromoustakos, A. Inhibitory effects of lactic and malic organic acids on autoinducer type 2 (AI-2) quorum sensing of Escherichia coli O157:H7 and Salmonella Typhimurium. LWT 2016, 66, 560-564. [CrossRef]

34. Pothitirat, W.; Chomnawang, M.T.; Supabphol, R.; Gritsanapan, W. Free radical scavenging and anti-acne activities of mangosteen fruit rind extracts prepared by different extraction methods. Pharm. Biol. 2009, 48, 182-186. [CrossRef]

35. Khan, M.; Zahin, M.; Hasan, S.; Husain, F.; Ahmad, I. Inhibition of quorum sensing regulated bacterial functions by plant essential oils with special reference to clove oil. Lett. Appl. Microbiol. 2009, 49, 354-360. [CrossRef]

36. Zhang, J.; Wang, H.; Huang, Q.; Zhang, Y.; Zhao, L.; Liu, F.; Wang, G. Four superoxide dismutases of Bacillus cereus 0-9 are non-redundant and perform different functions in diverse living conditions. World J. Microbiol. Biotechnol. 2020, 36, 12. [CrossRef]

37. Gao, T.; Ding, M.; Yang, C.-H.; Fan, H.; Chai, Y.; Li, Y. The phosphotransferase system gene ptsH plays an important role in MnSOD production, biofilm formation, swarming motility, and root colonization in Bacillus cereus 905. Res. Microbiol. 2019, 170, 86-96. [CrossRef]

38. Zhang, J.; Xiao, Y.; Guan, Y.; Rui, X.; Zhang, Y.; Dong, M.; Ma, W. An aqueous polyphenol extract from Rosa rugosa tea has antiaging effects on Caenorhabditis elegans. J. Food Biochem. 2019, 43, e12796. [CrossRef]

Sample Availability: Samples of the compounds are available from the authors.

Publisher's Note: MDPI stays neutral with regard to jurisdictional claims in published maps and institutional affiliations.

(C) 2020 by the authors. Licensee MDPI, Basel, Switzerland. This article is an open access article distributed under the terms and conditions of the Creative Commons Attribution (CC BY) license (http://creativecommons.org/licenses/by/4.0/). 